\title{
Effects of freeze-thawing processes on soil water transport in degraded agricultural areas
}

\author{
Libo Sun ${ }^{1}$, Xiaomin Chang ${ }^{1}$, Xinxiao $\mathrm{Yu}^{1}$, Guodong Jia ${ }^{1}$, Lihua Chen ${ }^{1}$, Yusong Wang ${ }^{1}$, \\ and Ziqiang Liu ${ }^{1}$ \\ ${ }^{1}$ Beijing Forestry University
}

August 17, 2020

\begin{abstract}
Seasonal freeze-thawing affects soil water migration and distribution, especially in semi-arid degraded agricultural areas, with important impacts on crop production, and wind erosion. We assessed the distribution and migration of soil water in degraded agricultural areas during freeze-thawing and the effect on plant growth and wind erosion. Soil water content (SWC) and soil temperature (ST) dynamic characteristics at a depth of 0-2 $\mathrm{m}$ in the semi-arid agro-pastoral northern China are discussed, using data from November 2018 to May 2019. Changes in water potential energy and pore pressure gradient caused soil water migration to the upper layer, which led to a slight decrease in SWC at each layer before ST dropped to the freezing point. The vertical migration distance of soil water exceeded $70 \mathrm{~cm}$, and the SWC above a depth of $100 \mathrm{~cm}$ increased significantly during thawing; the water was mainly obtained from the soil layer below a depth of $120 \mathrm{~cm}$. The initial SWC is the main factor affecting the freeze-thawing process. Our results can partly explain the occurrence of wind erosion in spring and provide a scientific basis for predicting soil water status and developing irrigation and erosion control strategies.
\end{abstract}

\section{Introduction}

Freeze-thawing processes in soil significantly impact agro-ecological conditions (Wang et al., 2019). They promote the migration of soil water and alter water distribution and hydrothermal coupling (Ala et al., 2016; Evett et al., 2012; Wei et al., 2018). Especially under the influence of spring windy weather and tillage activities, freeze-thawing processes can significantly change the soil structure and affect soil particle migration, making surface soil more prone to wind erosion (Ban et al., 2016). Changes in the soil water content (SWC; \%) of the upper layer can also affect irrigation strategy and crop growth during spring sowing (Wei et al., 2019). Based on a previous study, water and soil particle migration can also alter carbon and nitrogen cycling (CN cycle) in the soil (D'Odorico et al., 2003), facilitating soil erosion and affecting the microclimate.

During soil freezing, soil water freezes into ice crystals, forming a freezing front below 0 (Hou et al., 2020) and causing soil water to move from the unfrozen area to the freezing front (Nagare et al., 2012), resulting in a significant increase in SWC in frozen soil, and this process is also accompanied by the transfer of soil organic carbon. The SWC distribution prior to soil freezing in early winter will affect the soil water status in the following year (Luo et al., 2003), leading to an increase in field carbon storage and a reduced need for irrigation (Chen et al., 2013). In spring, increasing temperatures cause the upper soil to thaw first, while the lower soil layers gradually thaw over time. Hence, the increase in the SWC of the upper soil is more obvious (Yang et al., 2008).

In areas with low precipitation, the increased SWC caused by freeze-thawing represents an important water source for plants and crops. Thus, evaluating freeze-thawing processes in different soils and regions is 
critical for the management of degraded agricultural and forested areas, facilitating the development of management strategies. Several studies have investigated the mechanisms of SWC movement during soil freeze-thawing processes under different conditions (Nagare et al., 2011; Wang et al., 2019), focusing on the effects of different initial SWC on the freeze-thawing process. Based on the results, SWC and soil properties significantly influence freezing time and ground thermal condition. At the same time, the phases of water and ice are in equilibrium under temperature changes due to soil freezing, regardless of the thickness of the ice phase; the level of the liquid water is relatively stable (Low et al., 1968).

In agricultural freeze zones, the amount of water that migrates upward during freeze-thawing is controlled by the initial SWC; the lower the SWC, the more susceptible the soil is to freeze (Chen et al., 2013). However, the migration characteristics of soil water under freeze-thawing conditions in degraded agricultural areas are still unclear, and the influences of soil water migration, temperature changes, and related spatio-temporal conditions on wind erosion in degraded agricultural areas need to be elucidated (Wang et al., 2019).

In China, seasonal freeze-thawing events mostly occur in arid and semi-arid regions (Chen et al., 2013), with significant impacts on crop and tree growth. In the 1970s, large areas of agroforestry shelterbelts have been established in northern China, interlacing agro-pastoral regions to prevent wind erosion on farmland (Liu et al., 2018). However, large-scale farmland degradation under drought conditions has caused serious wind erosion and air pollution in farmland (Sun et al., 2018; Sun et al., 2019), significantly impacting the regional ecological environment. These problems have made farmland degradation more serious. Low precipitation and seasonal changes, as well as low SWC levels, facilitate wind erosion and low crop yields (Sun et al., 2019). Previous research has shown that the groundwater level in the area is declining constantly (Nakayama et al., 2010; Sun et al., 2018), potentially causing long-term dry conditions and severe wind erosion. However, there is still a lack of understanding of the impacts of freeze-thawing on soil water dynamics in this area. In this sense, this study aims to improve our understanding of the characteristics of soil temperature (ST; ) and water migration during freeze-thawing of degraded farmland, thereby facilitating the establishment of improved management strategies to prevent wind erosion.

\section{Materials and methods}

\section{Study site}

This study was conducted in Zhangbei County $\left(40^{\circ} 01^{\prime}-42 \operatorname{deg} 17^{\prime} \mathrm{N}, 114 \mathrm{deg} 05^{\prime}-115 \mathrm{deg} 20^{\prime} \mathrm{E}\right)$, which is part of the semi-arid agricultural freeze-thawing area in north China (Fig. 1a). Average annual rainfall is $320 \mathrm{~mm}$, of which $65 \%$ occur from June to September (Fig. 2). Elevation is about 1,750 m. The difference between day and night temperatures is significant. Annual average temperature increased over time, with values from 1.8-5.2degC $\left(\mathrm{R}^{2}=0.53, \mathrm{p}<0.01\right)$. Average annual wind speed is $6 \mathrm{~m} / \mathrm{s}$, and windy weather usually occurs in spring, especially in April. average relative humidity was $57.1 \%$. Winter is cold and lasts up to 5 months (November to March), and the average temperature can reach - 16 . Soil depth can be up to 450 $\mathrm{cm}$, with sandy soil being the main soil type. In the past 60 years, wind erosion and constant drought have reduced crop production, lead to severe land degradation. The species most frequently used in afforestation is Populus simonii Carr (Fig. 1b), which was first planted in the 1960s to prevent wind erosion.

\section{Freeze-thawing monitoring}

Since the root systems of the main crops and plants are distributed throughout the 0-200 $\mathrm{cm}$ soil layer (Liu et al., 2020), we investigated the soil profile up to a depth of $200 \mathrm{~cm}$. Environmental data were collected using a standard automatic weather station located in an open space a $20 \mathrm{~m}$ away from the study site. Precipitation ( $\mathrm{mm})$, temperature (), and relative humidity (\%) were measured at intervals of 15 mins. We used a battery-powered HOBO U30 NRC data logger (ONSET Computer Corporation, USA), which was charged daily using a photovoltaic power source.

Freeze-thawing processes were measured next to the meteorological observation sites. Briefly, the ST () and SWC (\%) were measured at intervals of 15 min via 10 5TE probes (Decagon, USA) placed at 10 soil depths $(10,30,50,70,90,110,130,150,170$, and $190 \mathrm{~cm})$. For this, we used a battery-powered EM50 data logger 
(Decagon, USA). Three monitoring points were randomly set up in the observation site, and the average data of each layer was calculated as the analysis data. The state of the soil was based on the ST; when ST is sustained below 0 , the soil begins to freeze, otherwise, it starts to thaw. Measurements were taken from November 1, 2018, to May 26, 2019.

\section{Results}

\section{Stratification of initial soil characteristics}

The initial SWC and ST profiles are shown in Figure 3. The lowest ST occurred at the surface of the soil, with 1.58. The ST reached a maximum value of 5.95 at a depth of $1 \mathrm{~m}$ and decreased significantly when the soil depth exceeded $1 \mathrm{~m}$. The ST changes were not obvious within the range of 1-2 $\mathrm{m}$, and ST was maintained around 3. At the beginning of soil freezing, the ST at all depths was above 0, higher than air temperature. The SWC also reached the maximum level at a depth of $1 \mathrm{~m}$, and at $90 \mathrm{~cm}$, it was nearly nine times higher than at $110 \mathrm{~cm}$. The SWC values at 110, 130, 150, 170, and $190 \mathrm{~cm}$ were 2.02, 1.98, 3.38, 1.58, and $2.12 \%$ respectively.

\section{Freeze-thawing processes with depth}

Surface soil $(0-20 \mathrm{~cm})$ started to freeze on November 10, 2018 (Table 1); ST was about 10 at a depth of 180 $\mathrm{cm}$. The upper soil frozen earlier than the deeper soil layer (Fig. 4b); for every $20 \mathrm{~cm}$ increase in depth, soil freezing was delayed for about 7 days (Table 1). The frozen soil layer reached a depth of $100 \mathrm{~cm}$ after 42 days and of $200 \mathrm{~cm}$ after 67 days. However, because of the fluctuating air temperature, the freezing depth was not constant. Air temperature was constantly below -10degC from December 10, and there were two significant cooling events on December 1 and 19 (Fig. 4a). During freezing, ST fluctuated significantly between -15 and 10 in the upper profile $(0-60 \mathrm{~cm})$. The lowest ST was $-18.55 \mathrm{deg} \mathrm{C}$ at the surface layer and $-2.95 \mathrm{degC}$ at a depth of $200 \mathrm{~cm}$.

Surface ST increased to levels above 0 and soil started to thaw on March 16, 2019 (Fig. 5). Temperature fluctuations in this period were monitored under near-freezing/thawing conditions. Soil at the depths of 100 and $200 \mathrm{~cm}$ began to thaw after 18 and 26 days, respectively. Full thawing of the surface soil first occurred on April 25. Compared with the surface soil, total thawing at 100 and $200 \mathrm{~cm}$ was delayed by 28 and 35 days, respectively (Table 1). Soils with a depth of $0-40 \mathrm{~cm}$ had greater temperature fluctuations during thawing, and ST fluctuations below $80 \mathrm{~cm}$ were not significantly affected by air temperature (Fig. 5). After thawing, the ST at a depth of 100-200 cm was maintained at around 7. The average time from the beginning to full thawing was about 26 days, in which the upper soil $(0-80 \mathrm{~cm})$ thawed more rapidly, at an average time of 21 days, while the $80-200-\mathrm{cm}$ soil layer took about 30 days to thaw completely.

Based on our results, ST was positively correlated with air temperature, except at a depth of 160-200 $\mathrm{cm}$ (Table 2). Compared with the upper soil, the deeper soil layer (below $60 \mathrm{~cm}$ ) was less affected by air temperature (Fig. 5). Figure 6 shows the dynamic response of surface ST $(0-60 \mathrm{~cm})$ to air temperature. Upper ST $(0-60 \mathrm{~cm})$ was strongly linearly correlated with air temperature $(\mathrm{y}=\mathrm{ax}+\mathrm{b})$; the regression equation explained more than $68.8 \%$ of the change. Coefficient 'a' represents for thermal efficiency between air and soil in the equation, which changed with changes in soil properties. The larger 'a' indicates that the heat transfer between ST and air temperature was more rapid; AT had a significant relationship with STs in the upper layers (Fig. 6; $\mathrm{P}$ 0.05). The closer to the surface, the more rapidly the ST responded to changes in air temperature.

Figure 7 shows the spatial and temporal variations in SWC at different soil depths. From December 1 to 7 , 2018 , soils at $0-20 \mathrm{~cm}$ froze rapidly as the air temperature dropped from -2.1 to $-22.6 \mathrm{degC}$ within a short period of time. Prior to freezing, there were significant differences in SWC in each layer (Fig. 7b), with SWC at $80-100 \mathrm{~cm}$ depth reaching a maximum of $18.99 \%$. Affected by cooler conditions on December 3 and 5 (Fig. 7a), the surface soil quickly froze, and the frozen layer extended downward. From January 10 onward, the soil layer at a depth of 0-200 cm was completely frozen. The SWC decrease ranged from 2 to $8 \%$ after the freezing front. Because of the absence of significant precipitation, SWC was less affected by precipitation. 
Since there was a stable phase from freezing to thawing, such a phase lasted longer in the deeper soil layers (Fig. 7b). The SWC increased slightly during thawing, indicating the upward migration of soil water, and each layer followed the same trend. From March 16 to April 5, 2019, ST fluctuated considerably (Fig. 7b), leading to a rapid increase in surface SWC. The SWC levels at 10, 30, 50, 70, and $90 \mathrm{~cm}$ increased by 85.7, $123,51,43.7$, and $29.2 \%$, respectively, which only slightly affected the deeper layer. From April 5 onward, the air temperature gradually increased, leading to significant changes in SWC $(\mathrm{p}<0.05)$.

The development of the soil freezing and thawing front with depth differed over time (Fig. 8), and each layer of soil froze more slowly than it thawed. The freezing front reached a depth of $60 \mathrm{~cm}$ for 13 days (November 12 to 15, 2018; Fig. 8a). However, it took much longer for the thawing front to reach the same depth (March 23 to April 13, 2019; Fig. 8b). Unlike the frozen front, which propagated from the surface to the deeper soil layers (Fig. 8a), the propagation of the thawing front was interrupted at some depths (Fig. 8b), such as 70, 110 , and $170 \mathrm{~cm}$. The duration of these melting fronts varied widely at depths of 110 to $170 \mathrm{~cm}$ (Fig. 8b), possibly due to air temperature variations.

\section{SWC migration during the freeze-thawing process}

The SWC within a depth of 0-100 cm changed significantly during freeze-thawing; the level was highest at $90 \mathrm{~cm}$ (Fig. 9a). At a depth below $100 \mathrm{~cm}$, SWC decreased significantly. After freeze-thawing, the SWC above $140 \mathrm{~cm}$ increased, which was most pronounced at a depth of $50 \mathrm{~cm}$ (Fig. 9b). The SWC at a depth of $150 \mathrm{~cm}$ was reduced by $1.9 \mathrm{~mm}$, while the levels at 170 and $190 \mathrm{~cm}$ almost remained stable. This suggests that soil water at a depth of $150 \mathrm{~cm}$ moved up to a depth of 110-130 cm. During the entire freeze-thawing process, there was a significant difference between the SWC levels at a depth of $90 \mathrm{~cm}$ and at the deeper soil layers, indicating that vertical soil water transport was impeded.

\section{Discussion}

\section{Freeze-thawing characteristics of soil}

Freeze-thawing processes in soil involve complex chemical, physical, and mechanical phenomena which mainly include energy, water transfer, and salt accumulation (Qi et al., 2018). This may lead to reduced soil compaction and changes in vegetation coverage, thus affecting various hydrological processes (Yamazaki et al., 2006). Soil freeze-thawing dynamics are related to differences in initial SWC (Ala et al., 2016; Wang et al., 2019), which was confirmed in our study The winter freeze-up stage began when the freezing process of the active layer was finished and lasted for approximately 200 days. Based on the temperature variations, this stage can be subdivided into the winter cooling stage and the spring-warming stage. Prior to freezing, within the depth range of 0-100 cm, SWC gradually increased with increasing depth, and freezing was rapid (Fig. 7b). During the complete freezing stage, the liquid and solid water of the entire soil layer remained relatively stable. Soil at the depth of $80-100 \mathrm{~cm}$ maintained a relatively high SWC, which may be due to the release of heat during the solidification of the soil water at the stable freezing stage, so that the soil in this layer was not completely frozen. Some studies have also pointed out that different soil thermal conductivity values are mainly due to differences in SWC levels (Yi et al., 2014); lower SWC levels may result in higher thermal conductivity. Consequently, higher SWC will slow down the freeze-thawing process (see also Wang et al., 2019). Figure 3 also shows that the ST at a depth of 80-100 cm was higher than that in the deeper soil and remained relatively high throughout the freeze-thawing process. The SWC below a soil depth of $90 \mathrm{~cm}$ was significantly reduced, which can be related to soil texture (Arredondo et al., 2018). The SWC of unfrozen soil increases with increasing clay content (Stahli and Stadler, 1997), soil particles gradually grow from the upper to the deeper layer in the sedimentary cycle, and the deeper soil consists of coarser soil particles, so that the SWC of upper soil could be higher in bottom soils. Furthermore, the water-repellent layer blocks the vertical water transport, leading to insignificant changes during freeze-thawing (Wei et al., 2016). During freezing, the freezing peak slowly extended downward; when it reached a depth of $90 \mathrm{~cm}$, the freezing process slowed down, which was related to the lower SWC level at this depth. Since the temperature fluctuated obviously at the initial stage of soil thawing, the soil surface fluctuated, which made the thawing process faster than the freezing process. Since the thermal conductivity of ice is about four times higher 
than that of liquid water (Campbell, 1985), the freezing rate of liquid soil water gradually decreased. When the soil began to thaw, the ice in the frozen soil promoted heat transfer, which confirms that the thawing rate of the soil is greater than the freezing rate.

\section{The freeze-thawing cycle affects the redistribution of SWC}

The dynamic distribution of SWC reflects the water and energy state of the soil, which depends on water-soil interaction and physical soil properties (Chen et al., 2013). During freezing, unfrozen water in the soil moves to the frozen area, driven by the temperature difference, which is manifested by soil water accumulation at the frozen layer (water transport upward). At the same time, the increase in soil water at the frozen layer reduces the soil freezing rate, which provides sufficient time for the soil water to be transported upward. Our research also proved that the freezing rate gradually decreased during the freezing process (Fig. 7b).

When soil started to freeze, the ST gradient was the primary factor that drove vertical soil water migration. Before the ST drops to the freezing point, the water in the frozen soil may be redistributed to the freezing front (Dirksen and Miller, 1966). The phenomenon of a decreasing SWC was observed at various depths before the temperature dropped to the freezing point (Fig. 7b), which was consistent with previous observations (Dirksen and Miller, 1966) and indicates that a water potential gradient is necessary for a certain amount of soil water flow to the freezing front. The largest soil water potential appeared at a depth of $100 \mathrm{~cm}$, and soil water moved up rapidly under the combined influence of temperature difference and water potential, resulting in a significant increase in the SWC above $100 \mathrm{~cm}$. However, due to the temperature difference and the formation of ice, the water potential of the soil is reduced (Nagare et al., 2012) and the downward flow of water during the freezing process is impeded; for this reason, the change in SWC at a depth of 100-200 cm was not obvious (Fig. 9b). In addition, the freeze-thawing cycle may also significantly impact soil physical properties (Viklander, 1998), which will in turn affect the soil water distribution. The unfrozen water retained in the soil forms a large pore pressure gradient in the cold-warm junction area. Due to this pore pressure, soil with large pores can transport water to the area with small pores (Chen et al., 2013). This phenomenon can also partially explain the redistribution of soil water from the depth of $100 \mathrm{~cm}$ to the upper layer.

\subsection{Implications for degraded farmland wind erosion management}

The freeze-thaw cycle is an important factor influencing soil water conditions in agricultural areas and can considerably change the physical properties of the soil (Viklander, 1998). Freeze-thawing cycles increase the possibility of soil erosion by destroying soil bonds (Ala et al., 2016), especially in farmland areas subjected to wind. In terms of practical applications, some studies attempted to use water migration during seasonal freeze-thawing to improve the farmland and woodland water status in spring (Pei et al., 1994). Freezethawing can also destroy the structure of soil aggregates, thereby reducing soil strength, decreasing nutrient availability, and reducing soil compaction (Sjursen et al., 2005), thus changing vegetation coverage in the long term and facilitating wind erosion (Yamazaki et al., 2006). Some studies have shown that the freezethawing cycle increases soil erodibility (Bryan, 2000; Gao et al., 2018). For example, in a study by Ban et al. (2016), soil erodibility increased after freeze-thawing compared with non-frozen soil. In our study, the surface layer of the soil maintained a water content of $14 \%$ prior to freezing.

Soil water expands when frozen, which increases soil porosity and reduces the agglomeration of soil particles. After thawing, the soil generally becomes looser, facilitating wind erosion. Soil freeze-thawing cycles vary with soil types and depths. Seasonal and daily temperature changes caused soil to freeze and thaw repeatedly from upper to deeper layers. Fluctuations in surface soil ST were observed in our study and elsewhere; they can significantly change soil texture (Jamshidi et al., 2015; Gullu et al., 2014). In addition, windy weather in spring also increases the probability of dust events caused by wind erosion (Sun et al., 2019). Along with water migration, soil salt can accumulate and move upward continuously along the channels in the soil (Xue et al., 2017; Hansson and Lundin., 2006), resulting in soil salinization. Especially during freezing, salt migration effects are most significant (Hou et al., 2020), with profound impacts on crop growth. However, soil compaction reduces the occurrence of wind erosion. The $\mathrm{C} / \mathrm{N}$ cycles and soil wind erosion are strongly 
interrelated (Quinton et al., 2010). Specifically, soil erodibility increases with freeze-thawing, which further increases the horizontal migration of carbon and nitrogen. The movement of soil particles in the upper layer increases the accumulation of organic carbon, thereby reducing its decomposition. In addition, the increase in surface SWC due to the freeze-thawing will reduce the need for spring irrigation.

\section{Conclusions}

We evaluated the dynamic changes in SWC and ST during freeze-thawing in agricultural soils. During the study period, the freezing point and water migration as well as the distribution of SWC changed significantly. The initial SWC distribution seemed to control the upward water movement. The lowest ST was -18.92 and occurred at depths above $20 \mathrm{~cm}$, while the highest SWC $(19.79 \%)$ occurred at a depth of 80-100 cm. During freezing, the temperature affected the freezing front, resulting in a more rapid thawing process compared to the freezing process. Before the ST dropped to the freezing point, upward soil water migration caused a slight decrease in SWC in each layer. In general, freeze-thawing is affected by changes in water potential energy and pore pressure gradient, resulting in the migration of soil water to the upper layers. In addition, during the entire freezing process, the upper soil $(0-60 \mathrm{~cm})$ was significantly affected by temperature changes, and its ST levels and water content fluctuations were significantly stronger. Affected by freeze-thawing, the soil texture and physical properties will be greatly changed, the soil compaction will be reduced, and the soil particles will be more broken. This, in turn, increases wind erosion and the frequency of dust events in semi-arid agricultural areas, which might also alter carbon and nitrogen cycles. Soil thawing increased soil water storage in farmland, reducing reliance on irrigation. Our results provide a deeper understanding of soil freeze-thawing processes in semi-arid agricultural areas and their impacts on crops, facilitating the development of adequate management strategies.

\section{Acknowledgments}

This research was funded by the National Key Research and Development Program of China (2016YFC0500802) and the Beijing Municipal Education Commission (CEFF-PXM2019_014207_000099).

\section{Data Availability Statement}

The data that support the findings of this study are available from the corresponding author upon reasonable request.

\section{References}

Ala, M., Liu, Y., Wang, A.Z., \& Niu, C.Y. (2016). Characteristics of soil freeze-thaw cycles and their effects on water enrichment in the rhizosphere. Geoderma. 264, 132-139. https://doi.org/10.1016/j.geoderma.2015.10.008.

Arredondo, T., Balbuena, J.D., Sannwald, E.H., Moya, E.G., Loescher, H.W., Gutierrez, C.A., \& Robles, U.R. (2018). Does precipitation affects soil respiration of tropical semiarid grasslands with different plant cover types? Agric. Ecosyst. Environ. 251:218-225. https://doi.org/10.1016/j.agee.2017.09.034.

Ban, Y.Y., Lei, T.W., Liu, Z.Q., \& Chen, C. (2016). Comparative study of erosion processes of thawed and non-frozen soil by concentrated meltwater flow. Catena 148: 153-159. https://doi.org/10.1016/j.catena.2016.06.019.

Bryan, R.B. (2000). Soil erodibility and processes of water erosion on hillslope. Geomorphology 32: 385-415. https://doi.org/10.1016/S0169-555X(99)00105-1. 
Campbell, G.S. (1985). Soil Physics With BASIC-Transport Models for Soil-Plant System. Elsevier, Amsterdam, The Netherlands, New York, p. 150.

Chen, S., Ouyang, W., Hao, F., \& Zhao, X. (2013). Combined impacts of freeze-thaw processes on paddy land and dry land in northeast china. Science of The Total Environment. 456-457, 24-33. https://doi.org/10.1016/j.scitotenv.2013.03.059.

Dirksen, C., \& Miller, R.D. (1966). Closed-system freezing of unsaturated soil. Soil Sci Soc Am Proc. 30:168-73.https://doi.org/10.2136/sssaj1966.03615995003000020010x.

D'Odorico, P., Laio, F., Porporatobc, A., \& Rodriguez-Iturbec, I. (2003). Hydrologic controls on soil carbon and nitrogen cycles. ii. a case study. Advances in Water Resources. 26;59-70. https://doi.org/10.1016/S0309-1708(02)00095-7.

Evett, S.R., Schwartz, R.C., Casanova, J.J., \& Heng, L.K. (2012). Soil water sensing for water balance, ET and WUE.Agric Water Manag.104:1-9. https://doi.org/10.1016/j.agwat.2011.12.002.

Gao, X.F., Li, F.H., Chen, C., Ban, Y.Y., \& Gao, Y. (2018). Effects of thawed depth on the sediment transport capacity by melt water on partially thawed black soil slope. Land Degradation \& Development. 30: 84-93. https://doi.org/10.1002/ldr.3213.

Gullu, H., \& Khudir, A. (2014). Effect of freeze-thaw cycles on unconfined compressive strength of finegrained soil treated with jute fiber, steel fiber and lime. Cold Regions Science and Technology. 106: 55-65. https://doi.org/10.1016/j.coldregions.2014.06.008.

Hansson, K., \& Lundin, L.C. (2006). Equifinality and sensitivity in freezing and thawing simulations of laboratory and in situ data. Cold Reg. Sci. Technol. 44, 20-37. https://doi.org/10.1016/j.coldregions.2005.06.004.

Hou, R., Li, T., Fu, Q., Liu, D., Cui, S., Zhou, Z., Yan, P., \& Yan, J. (2019). Effect of snow-straw collocation on the complexity of soil water and heat variation in the Songnen Plain, China. Catena. 172:190-202. https://doi.org/10.1016/j.catena.2018.08.030.

Hou, R., Li, T., Fu, Q., Liu, D., Li, M., Zhou, Z., Yan, J., \& Zhou, S. (2020). Research on the distribution of soil water, heat, salt and their response mechanisms under freezing conditions. Soil and Tillage Research. 196. https://doi.org/10.1016/j.still.2019.104486.

Jamshidi, R.J., \& Lake, C.B. (2015). Hydraulic and strength properties of unexposed and freeze-thaw exposed cement-stabilized soils. Canadian Geotechnical Journal 52(3): 283-294. https://doi.org/10.1139/cgj2014-0100.

Liu, Z.Q., Jia, G.D., \& Yu, X.X. (2020). Variation of water uptake in degradation agroforestry shelterbelts on the North China Plain. Agric. Ecosyst. Environ. 287. https://doi.org/10.1016/j.agee.2019.106697.

Liu, Z., Jia, G., Yu, X., Lu, W., \& Zhang, J. (2018). Water use by broadleaved tree species in response to changes in precipitation in a mountainous area of Beijing. Agric. Ecosyst. Environ. 251, 132-140. https://doi.org/10.1016/j.agee.2017.09.021.

Low, P.F., Anderson, D.M., \& Hoekstra, P. (1968). Some thermodynamic relationships for soils at or below the freezing point: 1. Freezing point depression and heat capacity. Water Resour Res. 4:379-94. https://doi.org/10.1029/WR004i002p00379.

Luo, L.F., Robock, A., Vinnikov, K.Y., Schlosser, C.A., Slater, A.G., \& Boone, A. (2003). Effects of frozen soil on soil temperature, spring infiltration, and runoff: results from the PILPS 2(d) experiment at Valdai, Russia. J Hydrometeorol. 4:334-51. https://doi.org/10.1175/1525-7541(2003)4<334:EOFSOS>2.0.CO;2.

Nakayama, T., Yang, Y., Watanabe, M., \& Zhang, X. (2010). Simulation of groundwater dynamics in the North China plain by coupled hydrology and agricultural models. Hydrol. Process. 20 (16), 3441-3466. https://doi.org/10.1002/hyp.6142. 
Nagare, R.M. (2011). Coupled Heat and Water Transport in Frozen Organic Soils. Ph.D. thesis, The University of Western Ontario, London, Canada, ON, 191 pp.

Nagare, R.M., Schincariol, R.A., Quinton,W.L., \& Hayashi, M. (2012). Effects of freezing on soil temperature, freezing front propagation and water redistribution in peat: laboratory investigations. Hydrol. Earth Syst. Sci. 16, 501-515. https://doi.org/10.5194/hess-16-501-2012.

Pei, X.Y., Ai, J., Zhang, H.T., \& Liu, E.D. (1994). Relation between freezing and melting depth of soil and forest ecology. J. Northeast For. Univ. 22 (6), 71-77.

Qi, Z.J., Feng, H., Zhao, Y., Zhang, T.B., Yang, A.Z., \& Zhang, Z.X. (2018). Spatial distribution and simulation of soil moisture and salinity under mulched drip irrigation combined with tillage in an arid saline irrigation district, northwest China. Agric. Water Manag. 201, 219231.https://doi.org/10.1016/j.agwat.2017.12.032.

Quinton, J.N., Govers, G., Oost, K.V., \& Bardgett, R.D. (2010). The impact of agricultural soil erosion on biogeochemical cycling. Nature Geoscience. 3:311-314. https://doi.org/10.1038/ngeo838.

Sjursen, H., Michelsen, A., \& Holmstrup, M. (2005). Effects of freeze thaw cycles and thawing on microarthropods and nutrient availability in a sub-arctic soil. Applied Soil Ecology 28: 79-93. https://doi.org/10.1016/j.apsoil.2004.06.003.

Stahli, M., \& Stadler, D. (1997). Measurement of water and solute dynamics in freezing soil columns with time domain reflectometry. J Hydrol. 195:352-69. https://doi.org/10.1016/S0022-1694(96)03227-1.

Sun, L.B., Chang, X.M., Yu, X.X., Jia, G.D., Chen, L.H., Liu, Z.Q., \& Zhu, X.H. (2019). Precipitation and soil water thresholds associated with drought-induced mortality of farmland shelter forests in a semi-arid area. Agric. Ecosyst. Environ. 284.https://doi.org/10.1016/j.agee.2019.106595.

Sun, S.J., Qiu, L., He, C., Li, C., Zhang, J., \& Meng, P. (2018). Drought-Affected Populus simonii Carr. Show Lower Growth and Long-Term Increases in Intrinsic Water-Use Efficiency Prior to Tree Mortality. Forests. 9 (9), 564. https://doi.org/10.3390/f9090564.

Wang, T., Li, P., Li, Z., Hou, J., Xiao, L., Ren, Z., Xu, G., Yu, K., \& Su, Y. (2019). The effects of freezethaw process on soil water migration in dam and slope farmland on the Loess Plateau, China. Science of The Total Environment. 666: 721-730. https://doi.org/10.1016/j.scitotenv.2019.02.284.

Wei, F.L., Wang, S., Fu, B.J., Wang, L.X., Liu, Y.Y., \& Li, Y. (2019). African dryland ecosystem changes controlled by soil water. Land Degradation \& Development. 30: 1564-1573. https://doi.org/10.1002/ldr.3342.

Wei, X., Huang, C.H., Wei, N., Zhao, H. C., He, Y., \& Wu, X.D. (2018). The impact of freeze-thaw cycles and soil moisture content at freezing on runoff and soil loss. Land Degradation \& Development. 30: 515-523. https://doi.org/10.1002/ldr.3243.

Wei, X., Li, X.G., \& Wei, N. (2016). Fractal features of soil particle size distribution in layered sediments behind two check dams: implications for the Loess Plateau, China. Geomorphology. 266: 133-145. https://doi.org/10.1016/j.geomorph.2016.05.003.

Xue, K., Wen, Z., Zhang, M.L., Li, D.S., \& Gao, Q. (2017). Relationship between matric potential, moisture migration and frost heave in freezing process of soil. Trans. Chin. Soc. Agric. Eng. 33: 176-183.

Yamazaki, Y., Kubota, J., Ohata, T., Vuglinsky, V., \& Mizuyama, T. (2006). Seasonal changes in runoff characteristics on a permafrost watershed in the southern mountainous region of eastern Siberia. Hydrol. Process. 20: 453-467. https://doi.org/10.1002/hyp.5914.

Yang, J.F., Zheng, X.Q., \& Xing, S.Y. (2008). Experimental study of soil water regimes during seasonal freezing-thawing period under different surface mulching. J. Taiyuan Univ. Technol. 39 (3), 303-306. 
Yi, J., Zhao, Y., Shao, M.A., Zhang, J.G., Cui, L.L., \& Si, B.C. (2014). Soil freezing and thawing processes affected by the different landscapes in the middle reaches of Heihe River Basin, Gansu, China. J. Hydrol. 519, 1328-1338. https://doi.org/10.1016/j.jhydrol.2014.08.042.

Viklander, P. (1998). Permeability and volume changes in till due to cyclic freeze/thaw. Can Geotech J. 35:471-7. https://doi.org/10.1139/t98-015.

Table 1. Starting dates of the soil freezing-thawing stages in 2018-2019.

\begin{tabular}{lllll}
\hline Soil depth $(\mathrm{cm})$ & Freezing (month/day) & Completely frozen (month/day) & Thawing (month/day) & Completely thawed \\
\hline $0-20$ & $11 / 10$ & $12 / 31$ & $3 / 16$ & $4 / 25$ \\
$20-40$ & $11 / 19$ & $12 / 31$ & $4 / 7$ & $4 / 25$ \\
$40-60$ & $11 / 24$ & $12 / 31$ & $4 / 15$ & $4 / 27$ \\
$60-80$ & $12 / 8$ & $2 / 5$ & $4 / 17$ & $4 / 30$ \\
$80-100$ & $12 / 13$ & $2 / 18$ & $4 / 22$ & $5 / 23$ \\
$100-120$ & $12 / 21$ & $2 / 20$ & $4 / 20$ & $5 / 26$ \\
$120-140$ & $12 / 28$ & $2 / 23$ & $4 / 25$ & $5 / 28$ \\
$140-160$ & $1 / 3$ & $2 / 23$ & $4 / 29$ & $5 / 27$ \\
$160-180$ & $1 / 10$ & $2 / 24$ & $4 / 27$ & $5 / 28$ \\
$180-200$ & $1 / 11$ & $2 / 27$ & $4 / 30$ & $5 / 30$ \\
\hline
\end{tabular}

Table 2. Pearson's correlation and $\mathrm{R}^{2}$ values between air temperature and soil temperature at each soil depth in Zhangbei County.

\begin{tabular}{lll}
\hline Soil depth $(\mathrm{cm})$ & Pearson's correlation coefficient & $\mathrm{R}^{2}$ \\
\hline $0-20$ & $0.948^{* *}$ & 0.899 \\
$20-40$ & $0.900^{* *}$ & 0.810 \\
$40-60$ & $0.828^{* *}$ & 0.685 \\
$60-80$ & $0.727^{* *}$ & 0.528 \\
$80-100$ & $0.589^{* *}$ & 0.347 \\
$100-120$ & $0.496^{* *}$ & 0.247 \\
$120-140$ & $0.380^{* *}$ & 0.144 \\
$140-160$ & $0.247^{* *}$ & 0.061 \\
$160-180$ & 0.140 & 0.020 \\
$180-200$ & 0.094 & 0.009 \\
\hline
\end{tabular}

Fig 1. Map showing the study location; a and b represent Zhangbei County and P. simonii Carr shelterbelts, respectively.

Fig 2. Climate diagram for Zhangbei County covering the period from 1980-2018.

Fig 3. Initial soil temperature and soil water content levels for the study site in Zhangbei County.

Fig 4. The traces of the soil temperature in Zhangbei Country (10, 30, 50, 70, 90, 110, 130, 150, 170 and $190 \mathrm{~cm}$ depth; freezing-thawing progress from $1^{\text {st }}$ Dec. 2018 to $26^{\text {th }}$ May 2019$)$.

Fig 5. Dynamic variations in air temperature (a) and soil temperature (b) at depths of 10, 30, 50, 70, 90, 110, 130, 150, 170, and $190 \mathrm{~cm}$ throughout the experimental period in Zhangbei County.

Fig 6. Correlation between air temperature and upper soil temperature (0-20, 20-40, and 40-60 cm) in Zhangbei County. 
Fig 7. Dynamic variations in air temperature (a) and soil water content (b) at depths of 10, 30, 50, 70, 90, $110,130,150,170$, and $190 \mathrm{~cm}$ throughout the experimental period in Zhangbei County.

Fig 8. Changes in the freezing front (a) and the thawing front (b) at each soil layer in Zhangbei County.

Fig 9. Soil water content throughout the freeze-thawing period (a) and increase in the soil water content at different soil depths (b) (freeze-thawing period from December 1, 2019, to May 26, 2019).
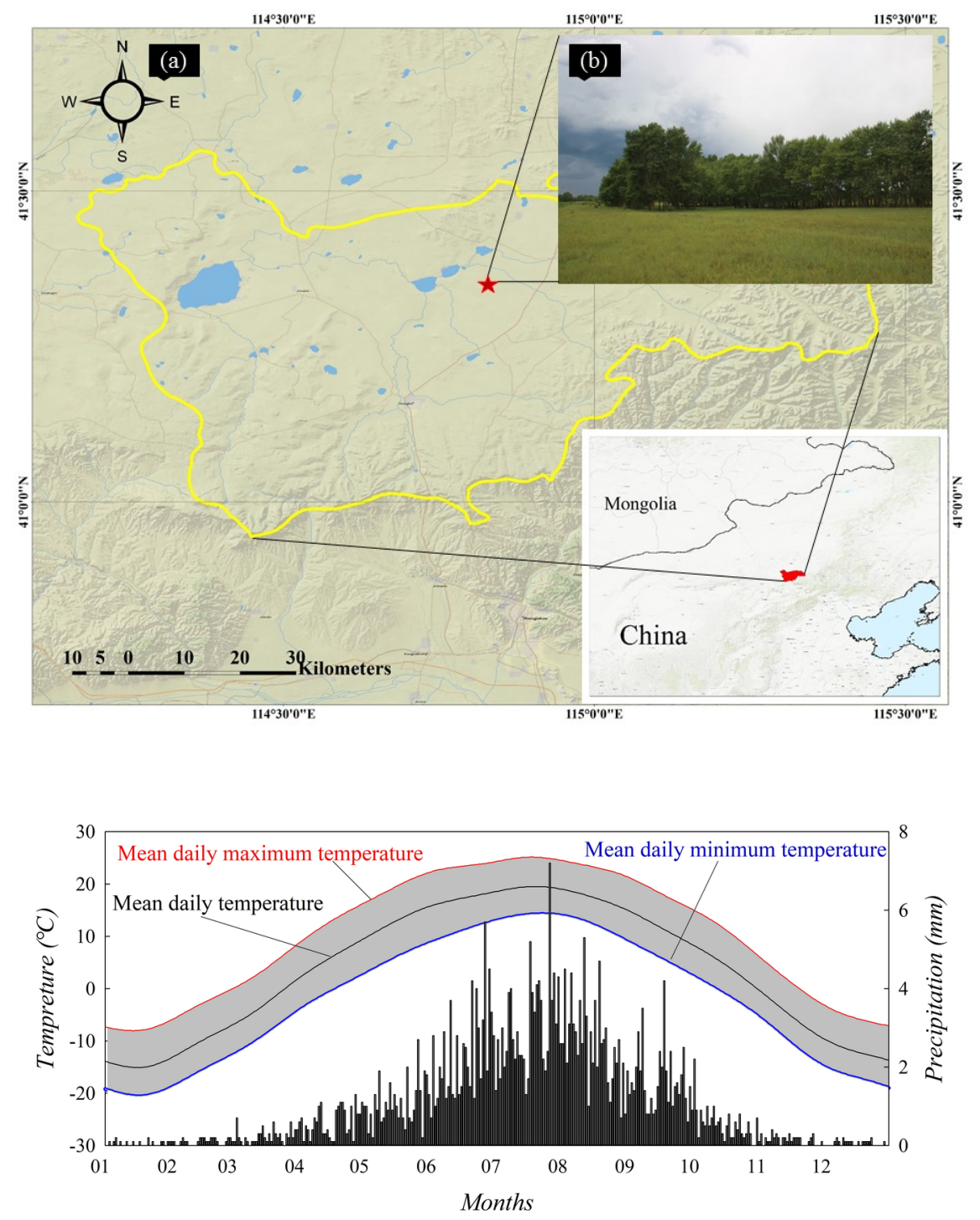

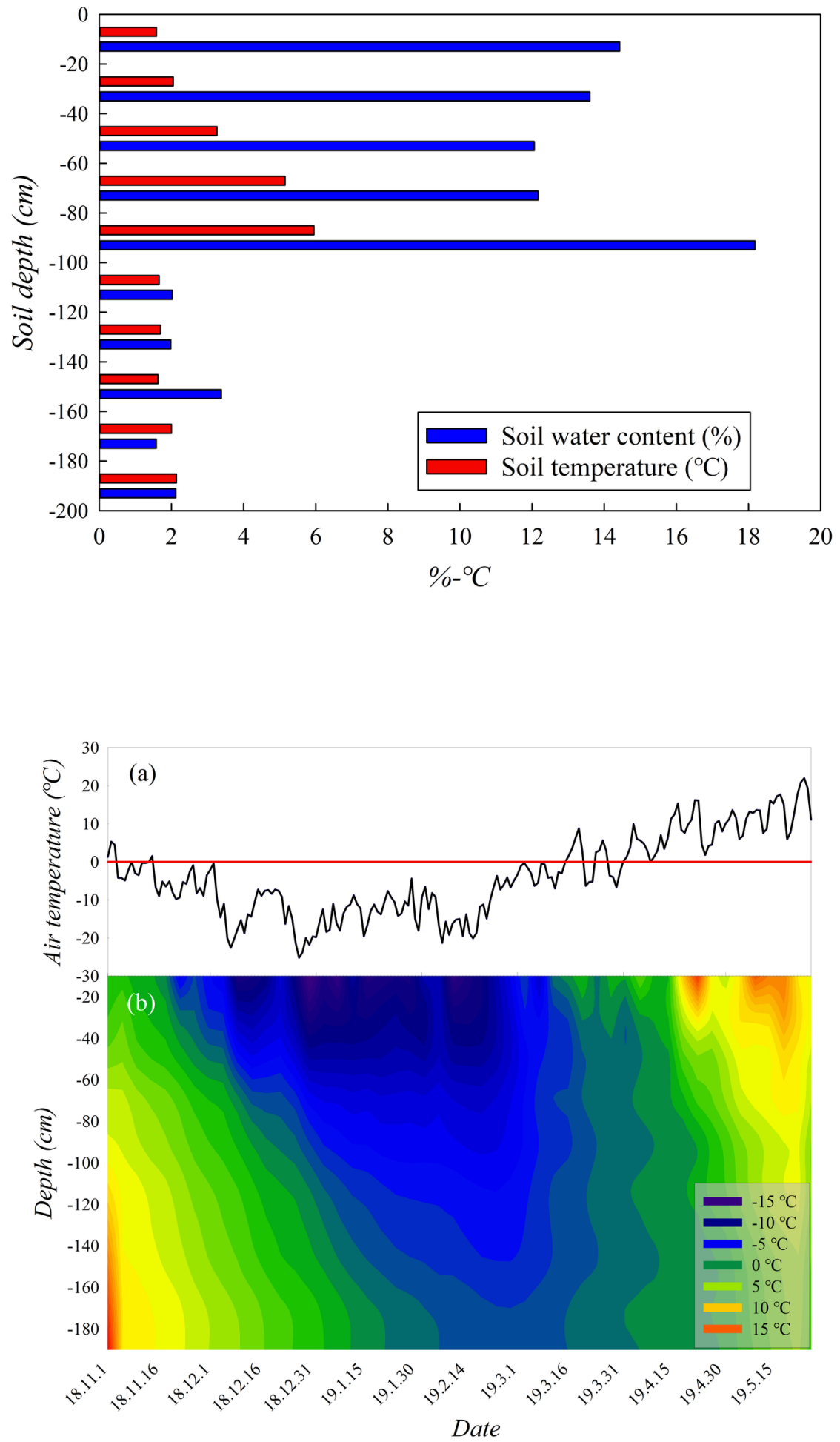

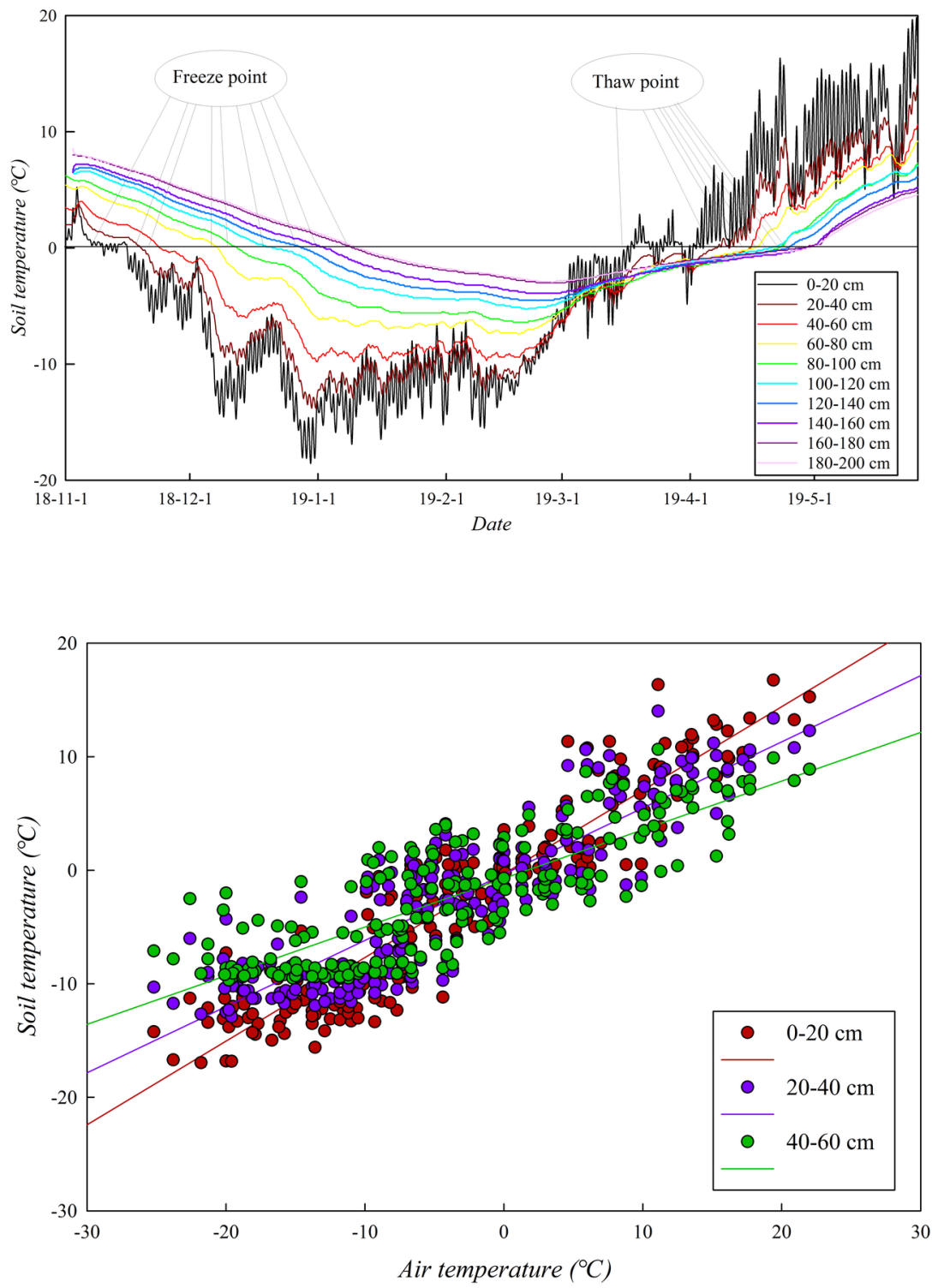


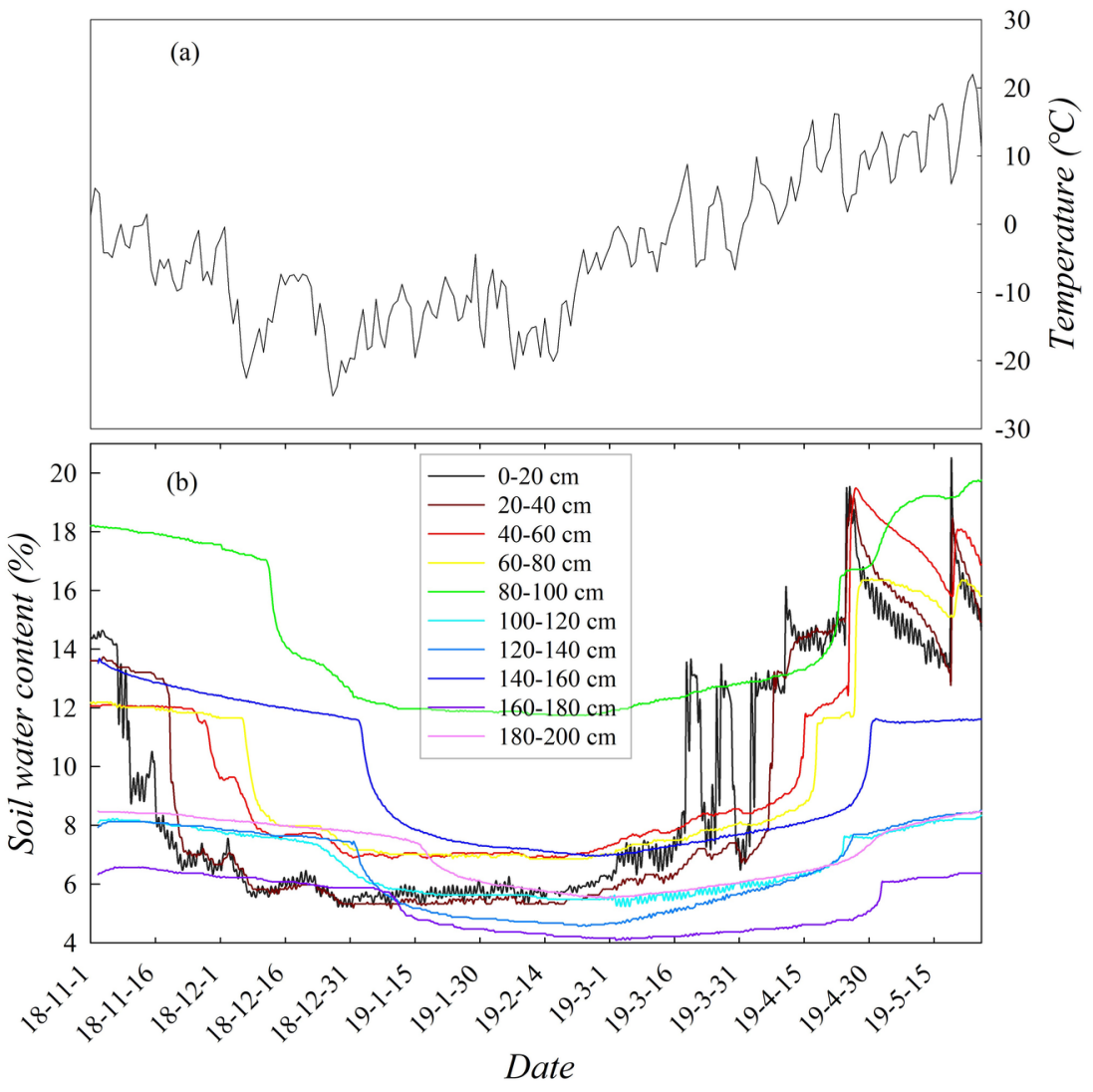



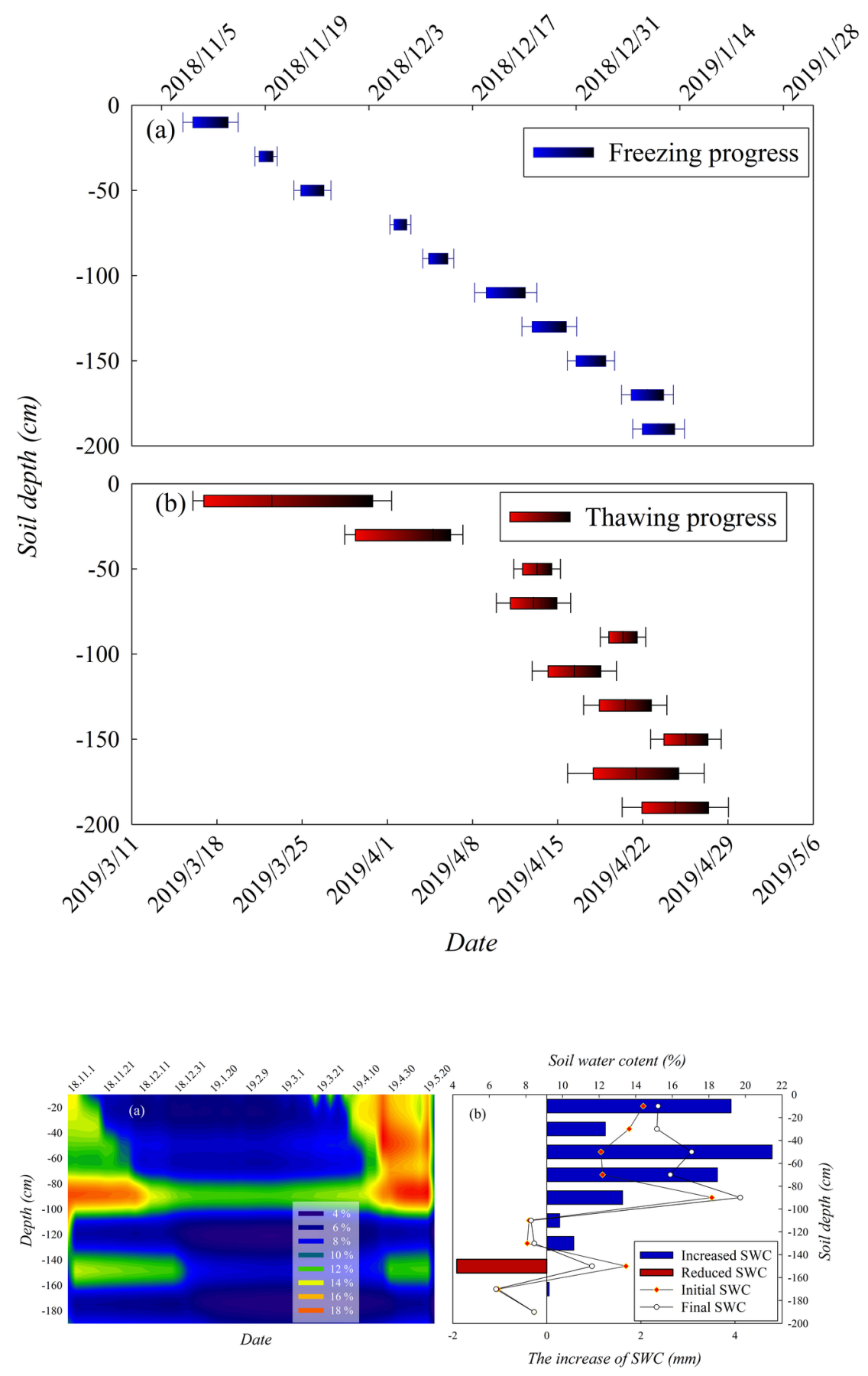